\title{
In-vitro Antibacterial Activity of Novel Nanostructured Composites Based on Forsterite and Silver Nanoparticles
}

\author{
ALEXANDRA AVRAM ${ }^{1}$, MARIA GOREA ${ }^{1}$, SORIN RAPUNTEAN ${ }^{2 *}$, AURORA MOCANU ${ }^{1}$, \\ GERTRUD ALEXANDRA PALTINEAN ${ }^{1}$, CSABA VARHELYI, JR. ${ }^{1}$, IOAN PETEAN ${ }^{1}$, \\ OSSI HOROVITZ1, MARIA TOMOAIA-COTISEL ${ }^{1,3 *}$ \\ ${ }^{1}$ Babes-Bolyai University of Cluj-Napoca, Research Center in Physical Chemistry, Engineering Department, Faculty of \\ Chemistry and Chemical Engineering, 11 Arany J. Str., 400028, Cluj-Napoca, Romania \\ ${ }^{2}$ University of Agricultural Sciences and Veterinary Medicine of Cluj-Napoca, 3-5 Manastur Str., 400372, Cluj-Napoca, \\ Romania \\ ${ }^{3}$ Academy of Romanian Scientists, 54 Splaiul Independentei, 050094, Bucharest, Romania
}

There is a continuous need for discovering new nanomaterials with antibacterial activity against various pathogens, like Staphylococcus aureus (S. aureus) and Escherichia coli (E. coli). This study was performed to assess the antimicrobial activity of two novel nanostructured forsterites, both in the absence and the presence of silver nanoparticles (AgNPs). The two nano forsterites (FS) were prepared by advanced sol-gel (FSsg) and precipitation (FSpp) methods. Preparation of colloidal AgNPs systems was realized by using the precursor, $\mathrm{AgNO}_{3}$, and the trisodium citrate and tanic acid assuring the formation and stabilization of AgNPs. The characterization of nano forsterite powders was carried out using complementary physical methods: XRD, SEM, and AFM. The AgNPs were characterized by UV-Vis spectra, STEM and AFM imaging. The antimicrobial activity was studied by the agar well diffusion method both in the FS native state, as FSsg and FSpp, and in their mixture with silver nanoparticles (AgNPs). The inhibitory effect of synthesized forsterites, FSsg and FSpp, particularly variants with AgNPs was found only on the S. aureus strain, the zones of inhibition being between 8 and $10 \mathrm{~mm}$, and more intensely expressed in the FSpp-AgNPs dispersions. These findings open new orthopedic applications of these systems, particularly for antimicrobial coated metallic implants.

Keywords: nano forsterite, silver nanoparticles, forsterite-AgNPs composites, antibacterial activity

Surgical infections are real complications in modern orthopedic surgeries involving orthopedic implants. The vast majority of infections are caused by Gram positive Staphylococcus aureus (S. aureus) strains. However, there are some infections (up to $23 \%$ of all orthopedic implant infection) caused by Gram negative bacilli, Escherichia coli (E. coli) being the main microorganism involved [1].

In the cases involving metallic prosthetic devices, bacteria tend to assemble in a biofilm on the surface of metallic substrates or, even penetrate into porous bones [2]. This fact can cause tissue contamination and trigger a local response that can lead to severe and chronic inflammation [3].

Moreover, bacteria frequently develop antibiotic resistance. In consequence, a wide variety of inorganic materials have been synthesized and studied over the last years, as coatings on metallic implants. While most of them involve the addition of silver nanoparticles, AgNPs, known for their antibacterial effect, there are some materials credited to possess intrinsic antibacterial properties. Magnesium oxide $(\mathrm{MgO})[4,5]$ and silicon dioxide $\left(\mathrm{SiO}_{2}\right)[6]$ are such examples.

The research regarding the antibacterial properties of forsterite (magnesium silicate, $\mathrm{Mg}_{2} \mathrm{SiO}_{4}$ ) is still in the early stages. For example, the simple forsterite powder presented no bactericidal properties at concentrations in the range of 25 $200 \mathrm{mg} / \mathrm{mL}$ [7]. However, a composite of forsterite and 58S bioglass did exhibit an activity at a concentration above 50 $\mathrm{mg} / \mathrm{mL}$. Furthermore, it was reported that a $2 \mathrm{mg} / \mathrm{mL}$ sol-gel glycine-derived forsterite has an ability to inhibit $S$. aureus while an urea-derived one exhibit the same effect on both $S$. aureus and E. coli [8]. The authors explain this activity of forsterite as a consequence of the increase in $\mathrm{pH}$ in the culture medium that is detrimental to bacterial development [8]. Certainly, the antibacterial mechanism of forsterite containing systems is not yet understood.

The aim of this study is to characterize and compare the antibacterial activity of two types of forsterite, synthesized by sol gel, FSsg, [9-12] and by precipitation route, FSpp, [13], in the absence and the presence of AgNPs.

\footnotetext{
*emailsorin.rapuntean@gmail.com; mcotisel@gmail.com
} 


\section{Experimental part}

Materials and methods

$\underline{\text { Synthesis of novel forsterite }}$

Novel forsterite, FSsg and FSpp, powder was prepared following 2 synthesis routes, namely sol-gel and precipitation.

\section{Sol-gel method to prepare FSsg}

Nanometric forsterite powder was synthesized using $99.5 \%$ pure magnesium nitrate hexahydrate $\left(\mathrm{Mg}\left(\mathrm{NO}_{3}\right)_{2} \cdot 6 \mathrm{H}_{2} \mathrm{O}\right.$, Merck) and tetraethyl orthosilicate $\left(\mathrm{C}_{8} \mathrm{H}_{20} \mathrm{O}_{4} \mathrm{Si}\right.$ - TEOS, Merck) as precursors, following a Mg:Si molar ratio of 2:1. Magnesium nitrate was dissolved in $200 \mathrm{~mL}$ ultrapure water. TEOS was then added. A quantity of sucrose 4 times the previously added amount of TEOS was dissolved in $400 \mathrm{~mL}$ ultrapure water. The dissolved sucrose was added drop by drop into the precursor mixture. The final solution was then homogenized on a magnetic stirrer for 2 hours. The $\mathrm{pH}$ of the solution was brought to 1 using nitric acid (65\%, Merck) followed by a second homogenization period of 2 hours at room temperature and a third one for another 2 hours at $80^{\circ} \mathrm{C}$. The final mixture was aged for 24 hours at room temperature to allow for gel formation. The formed gel was dried at $100^{\circ} \mathrm{C}$ in an air atmosphere until complete dehydration, resulting in a black, thick gel that was finally thermally treated at $900^{\circ} \mathrm{C}$ for 2 hours with a heating rate of $5^{\circ} \mathrm{C} / \mathrm{min}$.

\section{Precipitation method of FSpp}

The $99.5 \%$ pure magnesium nitrate hexahydrate $\left(\mathrm{Mg}\left(\mathrm{NO}_{3}\right)_{2} \cdot 6 \mathrm{H}_{2} \mathrm{O}\right.$, Merck) was disolved in ultrapure water. Tetraethyl orthosilicate $\left(\mathrm{C}_{8} \mathrm{H}_{20} \mathrm{O}_{4} \mathrm{Si}\right.$ - TEOS, Merck) was added to the solution following the molar ratio specific for forsterite. The mixture was homogenized using a magnetic stirrer. Sodium hidroxide was added until a $\mathrm{pH}$ of 12 was obtained after which the solution was homogenized for an hour. The obtained precipitate was separated from the supernatant and washed with ultrapure water. The washed precipitate is dried for 24 hours at room temperature and for another 24 hours at $100^{\circ} \mathrm{C}$. Next, the dried precipitate was subjected to a thermal treatment at $900^{\circ} \mathrm{C}$ for 2 hours, following a heating rate of $5^{\circ} \mathrm{C} / \mathrm{min}$.

\section{Synthesis of AgNPs}

Silver nanoparticles were obtained by co-reduction of silver nitrate $\left(\mathrm{AgNO}_{3}\right.$, obtained from Merck) with a mixture of trisodium citrate (C, purchased from Sigma-Aldrich), and tannic acid (T, purchased from Merck) aqueous solutions, added to the boiling $\mathrm{AgNO}_{3}$ solution, so that the molar ratios of the reactants was $\mathrm{AgNO}_{3}: \mathrm{C}: \mathrm{T}=1: 20: 0.1$, and the silver content was $0.25 \mathrm{mM}(27 \mathrm{mg} / \mathrm{L})$ in the resulted colloidal solution. The mixture was kept boiling under continuous stirring for 15 min, and then rapidly cooled with a water and ice mixture $[14,15]$. Therefore, AgNPs-C-T (1:20:0.1) were synthesized in aqueous medium.

\section{Preparation of forsterite and AgNPs composites}

Preparation of dispersions made of novel forsterite or forsterite-AgNPs composite was performed for the antimicrobial tests. Aqueous dispersions containing $4 \mathrm{mg} / \mathrm{mL}$, and distinctly $8 \mathrm{mg} / \mathrm{mL}$, of FSsg or FSpp were prepared at $\mathrm{pH} 7$ and $\mathrm{pH}$ 12. The $\mathrm{pH} 7$ was realized with mixture of phosphates and $\mathrm{pH} 12$ by addition of $10 \% \mathrm{NaOH}$ solution; they were stabilized by ultrasonication (ultrasonic processor Sonics Vibra-Cell, model VCX 750; Sonics \& Material Inc., Newtown, CT, USA) for $3 \mathrm{~h}$. The dispersions of forsterite-AgNPs composites were prepared by adding the forsterite powders to the $0.25 \mathrm{mM}$ AgNPs dispersions to attain a $4 \mathrm{mg} / \mathrm{mL}$ or $8 \mathrm{mg} / \mathrm{mL}$ in FS content, at $\mathrm{pH} 7$ and $\mathrm{pH} \mathrm{12}$, and followed by ultrasonication for $3 \mathrm{~h}$. The adsorbed $\mathrm{Ag}$ concentration on $4 \mathrm{mg}$ and $8 \mathrm{mg}$ fosterite was $0.67 \%$ and $0.34 \%$, respectively.

\section{Characterization methods}

XRD

The crystalline compounds of obtained powders were investigated using a Bruker D8 Advance diffractometer, with Co $\mathrm{K} \alpha_{1}=1.79026 \AA$, operated at $35 \mathrm{kV}$ and $40 \mathrm{~mA}$. The XRD pattern was collected for a $2 \theta$ range of $5^{\circ}$ to $65^{\circ}$, with a step size of $0.02 \% \mathrm{sec}$.

UV-VIS absorption spectra were measured using a Jasco UV/Vis V650 spectrophotometer, in the domain from 800 to $190 \mathrm{~nm}$ wavelength.

SEM images were performed with a Jeol 5600 LV scanning electron microscope on forsterite nanopowders.

STEM images of the AgNPs colloidal solution were obtained with a combined scanning electron (SE) and scanning transmission electron (TE) microscope, Hitachi HD-2700, operated at a maximum accelerating voltage of $200 \mathrm{kV}$.

AFM images were realized on layers of AgNPs and forsterite powders deposited on glass by adsorption from various dispersions. For AFM investigations, AFM JEOL 4210 equipment was used, operated in tapping mode [16-19] using 
standard cantilevers with silicon nitride tips (resonance frequency in the range of $200-300 \mathrm{kHz}$ and spring constant 17.5 $\mathrm{N} / \mathrm{m}$ ). The 2D- and 3D- topographies, and cross section profiles were processed by standard AFM procedures.

\section{Determination of the antibacterial effect}

Bacterial strains tested, Staphylococcus aureus 6538P (ATCC) and Escherichia coli 10536 (ATCC), were inoculated in glucose broth (5\%) and incubated for $24 \mathrm{~h}$.

The tested materials were FSsg and FSpp dispersions (FS: $4 \mathrm{mg} / \mathrm{mL}$ and $8 \mathrm{mg} / \mathrm{mL}$ ), each in pure water, in $\mathrm{pH} 7 \mathrm{and} \mathrm{pH}$ 12 medium, as well as the mixed FSsg-AgNPs and FSpp-AgNPs dispersions (with FS at $4 \mathrm{mg} / \mathrm{mL}$ or at $8 \mathrm{mg} / \mathrm{mL}$ ), each at $p \mathrm{H} 7$ and $p \mathrm{H} 12$ in aqueous medium. The concentration of AgNPs was maintained constant at $0.25 \mathrm{mM}$ in all investigated dispersions.

In order to determine the inhibitory effect, the classical diffusion susceptibility test was used in nutrient agar (Kirby Bauer), adapted for testing conditioned products in liquid form [20]. For this purpose, Petri dishes (90 mm diameter, divided into two halves) were used, with the Mueller Hinton medium (Merck KGaA Germany), in an amount of $25 \mathrm{ml}$ (to obtain a uniform layer, with a thickness of $3 \mathrm{~mm}$ ).

For inoculation, $1 \mathrm{~mL}$ of $24 \mathrm{~h}$ culture broth was used, from each test strain, respectively $S$. aureus 6538P ATCC and $E$. coli 10536 ATCC, brought to a density of 0.5 according to McFarland standards $\left(1.5 \times 10^{8} \mathrm{CFU} / \mathrm{mL}\right)$. Uniform dispersion over the entire surface of the plate was done with a Drigalski spatula. Excess fluid was removed by suction with a Pasteur pipette. After drying the agar surface (keeping them for 20 minutes on the thermostat with the lid slightly open), wells were cut in the agar gel $(6 \mathrm{~mm}$ in diameter). In these wells, a fixed amount of $20 \mu \mathrm{L} /$ well was distributed from each product/sample tested.

The plates were incubated at thermostat at $37^{\circ} \mathrm{C}$ for 24 hours. After this time, the results of the plates were interpreted, appreciating the presence or absence of culture development around the wells. In the case of the inhibitory effect, the diameter of the inhibition zones was measured (millimeters).

The plates were kept under observation for further 3 days, to observe if there were no changes in time, regarding the size of the inhibition zones.

\section{Results and discussions}

\section{Forsterite characterization}

XRD patterns

The XRD pattern is presented for FSsg powder in Figure 1 and for FSpp powder is given in Figure 2. Both XRD spectra show well crystalized phases with narrow, very well-defined peaks. Further, Figure 1 shows forsterite as a single phase and magnesium oxide $(\mathrm{MgO})$ only traces.

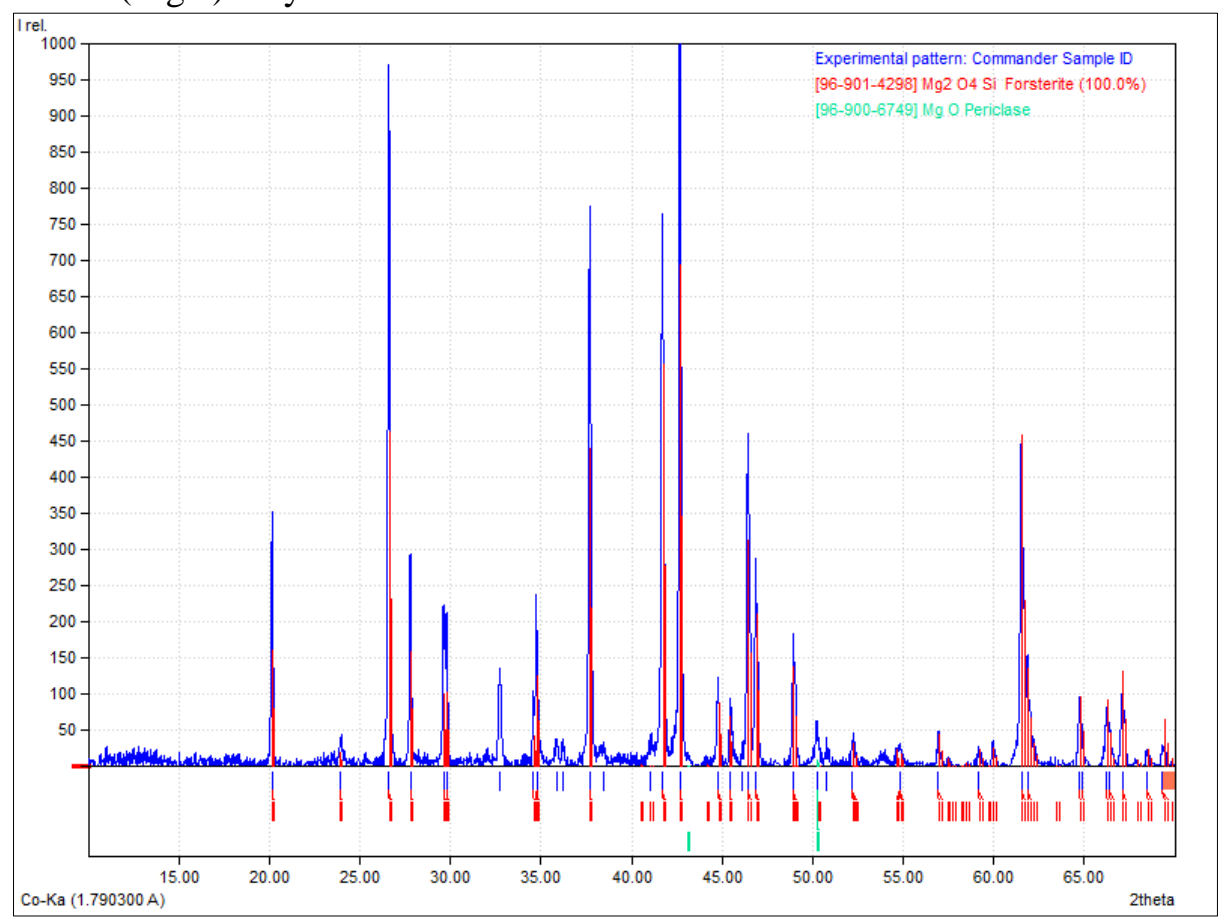

Fig. 1. X-ray diffraction pattern for FSsg powder 
Figure 2 evidences the predominant form of forsterite. However, the presence of some secondary phases, such as sodium magnesium silicate $\left(\mathrm{Na}_{2} \mathrm{MgSiO}_{4}\right)$ and magnesium oxide (periclase) traces, is also abserved. This characteristic can be explained by the use of $\mathrm{NaOH}$ as a $\mathrm{pH}$ regulator for precipitation.

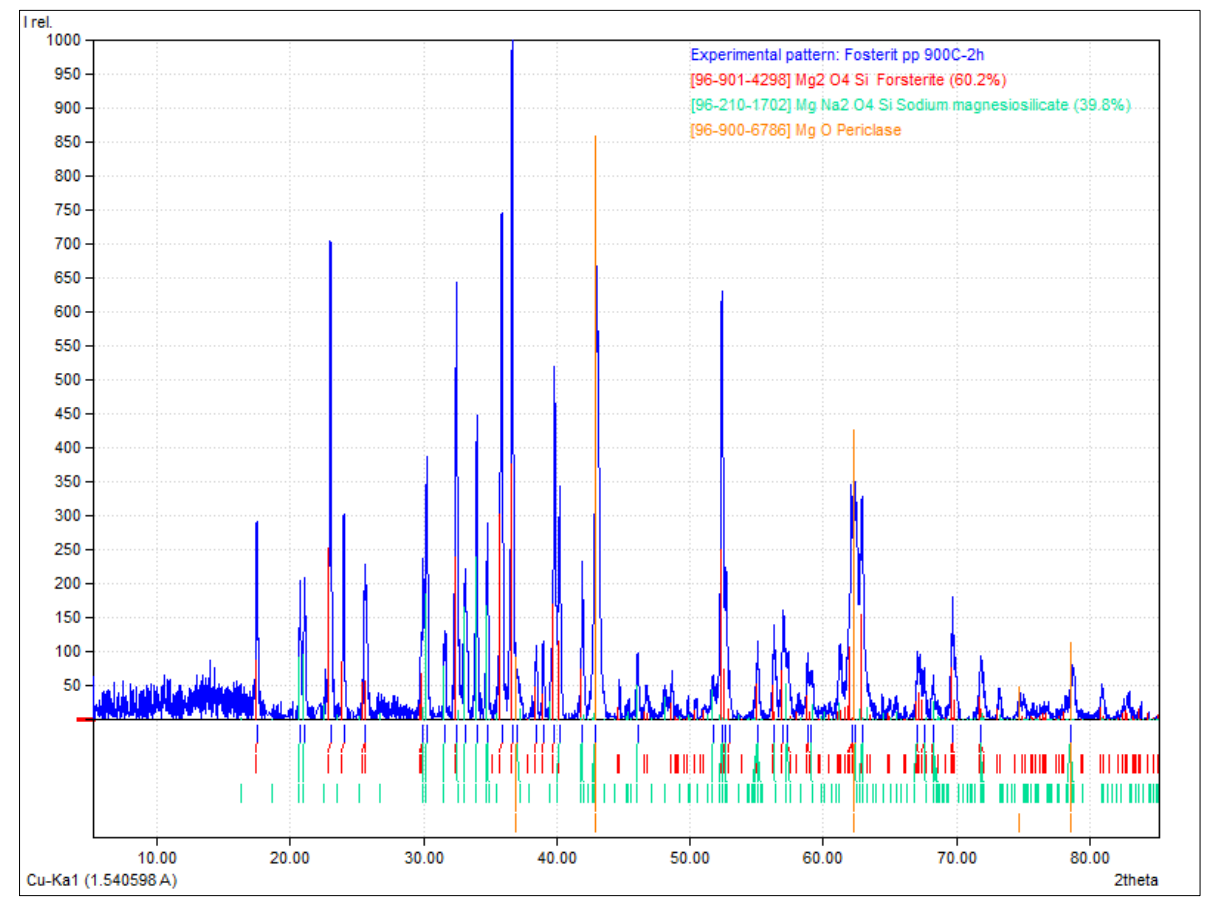

Fig. 2. X-ray diffraction pattern for FSpp powder

$\underline{\text { SEM investigation }}$

Figure 3 presents the morphologies of both FSsg (panel a) and FSpp (panel b) nanopowders. Figure 3 illustrates a welldispersed powder made of small crystalls with a gentle tendency of agglomeration within these powders.

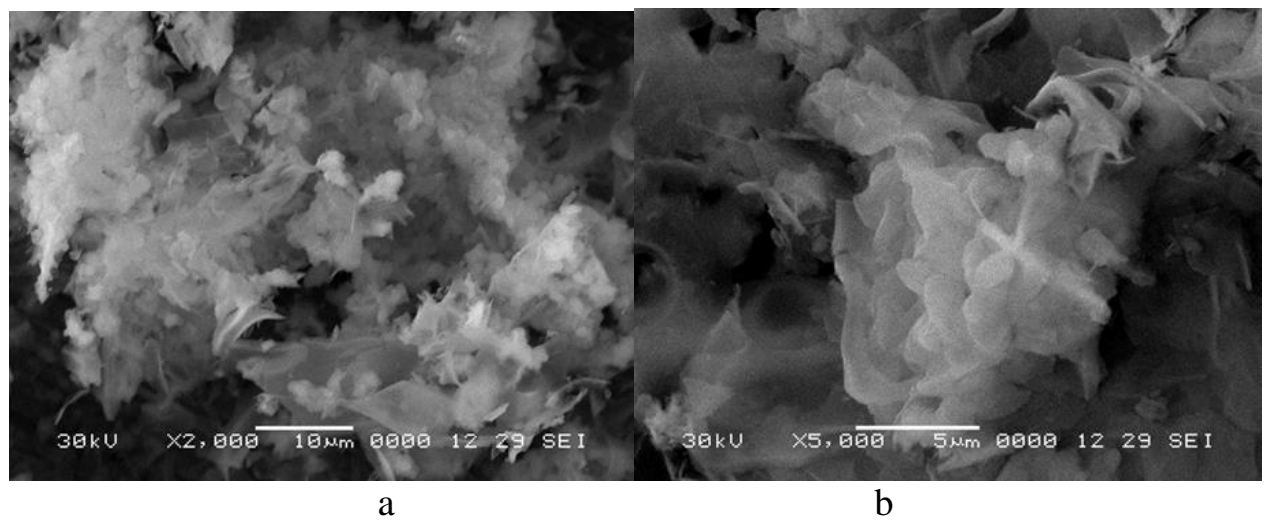

Fig. 3. SEM images on powders of FSsg (a) and FSpp (b)

\section{$\underline{\text { AFM investigation }}$}

Figure 4 presents the AFM images on adsorbed FSsg powder. The forsterite particles are well contoured with a tendency to form agglomerates. This is better observed in the 3D image (Figure 4b). The FSsg powder deposited on glass shows the RMS on scanned area of $80 \pm 4 \mathrm{~nm}$. The nanoparticle size is determined as $83 \pm 16 \mathrm{~nm}$ from the various profiles, as exemplified profile in Figure 4c. Moreover, the cross section profile indicates a tendency of FSsg to form some clusters with diameters of about $150 \mathrm{~nm}$. 


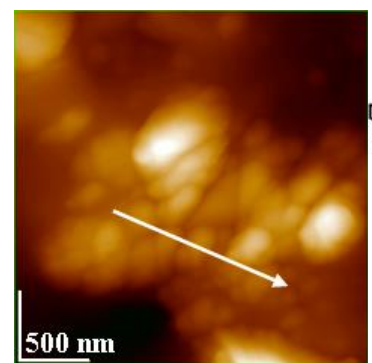

a

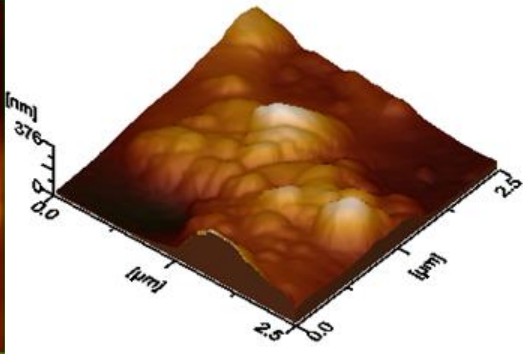

b

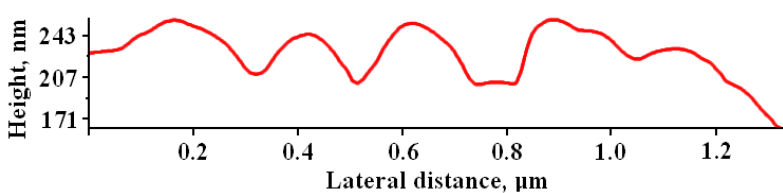

c

Fig. 4. AFM images on FSsg powder deposed on glass by adsorption from its aqueous dispersions: 2D topography (a), 3D-topography (b), and cross section profile (c); scanned area $2.5 \mu \mathrm{m} \times 2.5 \mu \mathrm{m}$, RMS on scanned area $80 \pm 4 \mathrm{~nm}$; nanoparticle size $83 \pm 16 \mathrm{~nm}$

Figure 5 presents the AFM images on FSpp powder. The deposited layer is rather uniform as identifed with a smooth and compact aspect with no clustering effect (panel a and b). The FSpp particles are well spread on the glass surface, they are of spherical shape with precise contours, Figure 5a. The smooth appearance is better observed in the 3D topography, Figure 5b. The FSpp layer has a very small roughness of only $2.4 \mathrm{~nm}$ on scanned area, as indicated in the profile, Figure $5 \mathrm{c}$. The particles diameter is $60 \pm 5 \mathrm{~nm}$.

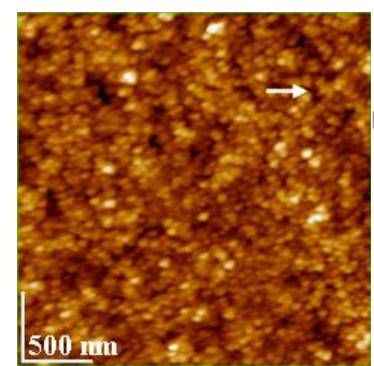

a

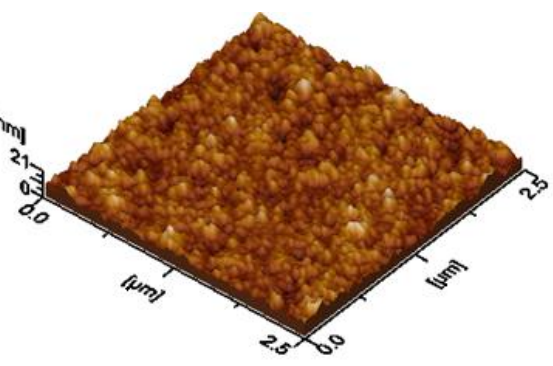

b

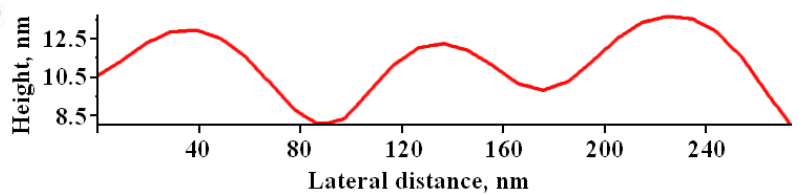

c

Fig. 5. AFM images on FSpp powder: a) 2D-topography, b) 3D-topography and c) cross section profile; scanned area $2.5 \mu \mathrm{m} x 2.5 \mu \mathrm{m}$; RMS on scanned area $2.4 \pm 0.2 \mathrm{~nm}$; nanoparticle diameter $60 \pm 5 \mathrm{~nm}$

\section{$\underline{\text { AgNPs characterization }}$}

The UV-Vis sprectra of the colloidal $0.25 \mathrm{mM}$ AgNPs solution revealed the characteristic surface plasmon resonance (SPR) band of silver nanoparticles (Fig. 6), with a maximum at $404 \mathrm{~nm}$. From the width of the band, a rather narrow distribution of the nanoparticle size can be inferred, while the position of the maximum is characteristic for small silver nanoparticles.

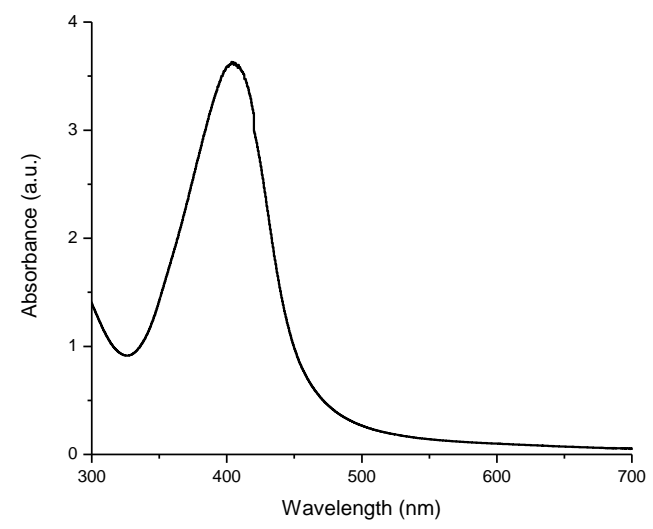

Fig. 6. The SPR band of silver nanoparticles obtained by reduction with $\mathrm{C}$ and $\mathrm{T}$, symbolized as AgNPs-CT or simple AgNPs

This conclusion is confirmed by the STEM image (Fig. 7). The AgNPs are characterized by an average diameter of about $10 \mathrm{~nm}$ in total agreement with AFM images (Fig. 8). 


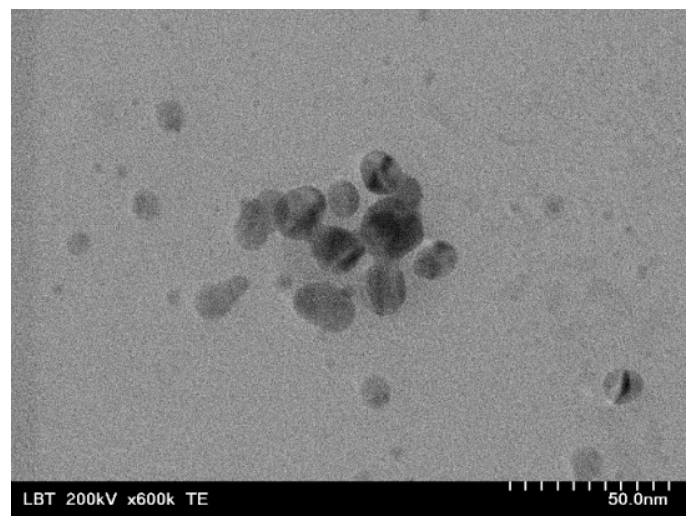

Fig. 7. STEM (TE) image for AgNPs

deposited on grids used in electron microscopy. A tendency of AgNPs to make aggregates is observed

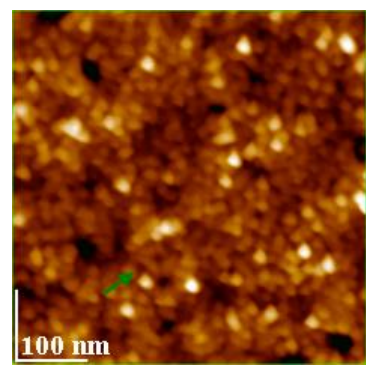

a

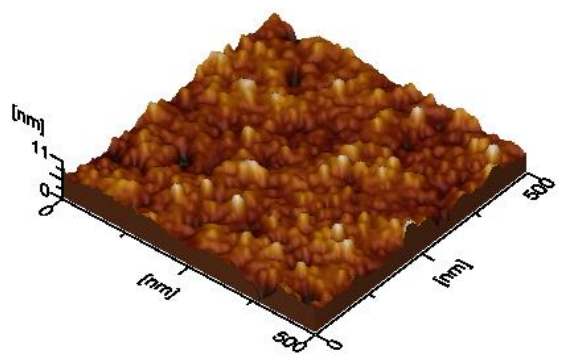

b

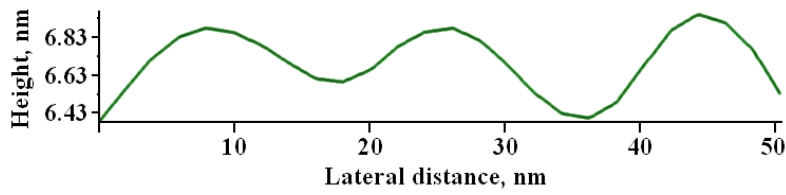

c

Fig. 8. AFM images: 2D-topography (a) and 3D-topography (b) of AgNPs deposited on glass by adsorption from aqueous dispersion; scanned area $0.5 \mu \mathrm{m} \times 0.5 \mu \mathrm{m}$; (c) cross section profile along the arrow in panel a; RMS on scanned area $1.2 \pm 0.1 \mathrm{~nm}$; nanoparticles diameter $10.2 \pm 0.5 \mathrm{~nm}$

\section{Antibacterial effect}

Forsterite sol-gel was investigated in the presence of AgNPs in neutral medium (pH-7) and in alkaline medium (pH12), versus FSsg content, at a constant amount of $0.25 \mathrm{mM} \mathrm{AgNPs,} \mathrm{in} \mathrm{these} \mathrm{aqueous} \mathrm{media.} \mathrm{Aspects} \mathrm{of} \mathrm{the} \mathrm{mode} \mathrm{of} \mathrm{action}$ of the FSsg product on tested strains are shown in Table 1 and Figs 9a and $9 \mathrm{~b}$.

Testing of the antibacterial effect of obtained forsterite, FSsg and FSpp, variants with AgNPs and variants, without AgNPs, namely forsterite in pure water, as well as in neutral $\mathrm{pH}$ and in alkaline $\mathrm{pH}$ media, was performed by the agar well diffusion method, against $S$. aureus and E. coli, as previously developed by us [21].

Table 1

FSsg CONTENT OF SAMPLES PREPARED IN TWO MEDIA OF pH 7 AND DISTINCTLY pH 12, AT THE SAME CONTENT IN AgNPs (0.25 mM), AND THE DIAMETER OF ZONES OF INHIBITION AT 24 h; TESTED STRAINS: S. aureus and E. coli.

\begin{tabular}{|c|c|c|c|c|}
\hline \multirow{4}{*}{ Tested strain } & \multicolumn{4}{|c|}{ Composite (product) characteristics } \\
\hline & \multicolumn{2}{|c|}{$\begin{array}{l}\text { AgNPs in aqueous medium of } \mathrm{pH}-7 \text {, versus } \\
\text { FSsg content }\end{array}$} & \multicolumn{2}{|c|}{$\begin{array}{c}\text { AgNPs in aqueous medium, of pH-12, } \\
\text { versus FSsg content }\end{array}$} \\
\hline & \multicolumn{4}{|c|}{ Diameter of inhibition areas $(\mathrm{mm})$ for the four wells } \\
\hline & $\mathbf{1}(4 \mathrm{mg} \mathrm{FSsg} / \mathrm{mL})$ & 3 (8 mg FSsg/ mL) & 2 (4 mg FSsg/ mL) & $4(8 \mathrm{mg}$ FSsg/ mL) \\
\hline S. aureus 6538P ATCC & 10 & 9 & 9 & 8 \\
\hline E. coli 10536 ATCC & 0 & 0 & 0 & 0 \\
\hline
\end{tabular}




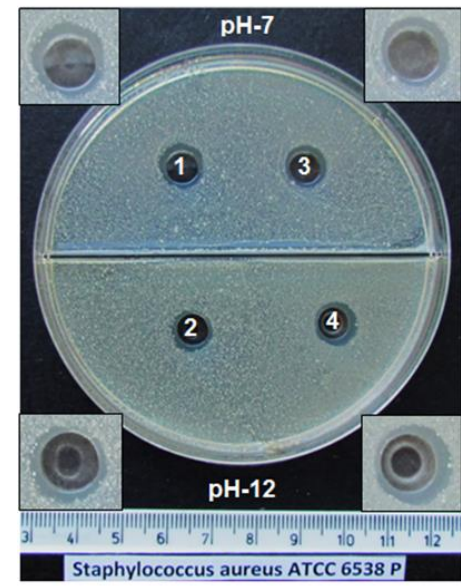

a

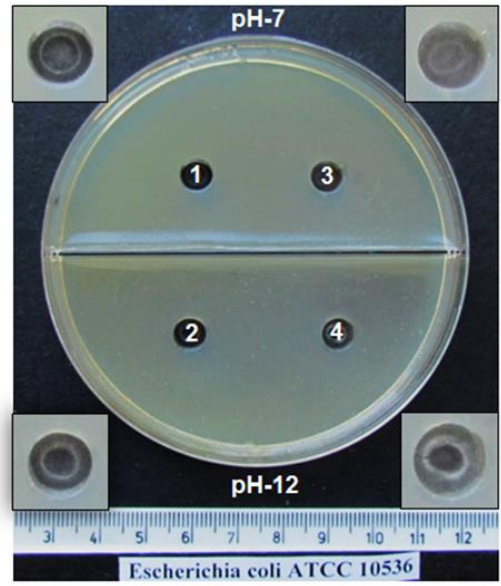

$\mathrm{b}$
Fig. 9. Inhibition zones for Staphylococcus aureus 6538P ATCC (a) and lack of inhibition for Escherichia coli 10536 ATCC (b), versus $\mathrm{pH}$ value and FSsg content. Wells are numbered according to their FSsg content and $\mathrm{pH}$ value, (see Table 1); well 1: $4 \mathrm{mg}$ of FSsg/mL, $p \mathrm{H}$ 7; well 2: $4 \mathrm{mg}$ FSsg/mL, $p \mathrm{H}$ 12; well 3: 8 mg FSsg/mL, $p \mathrm{H}$ 7; well 4: 8 mg FSsg/mL, $p \mathrm{H} 12$; each sample has the same content 0.25 $\mathrm{mM}$ AgNPs. Insets: magnified images for each well

From the analysis of the data listed in Table 1 and Figs 9a and 9b, it can be seen that the FSsg product had only inhibitory effect on the $S$. aureus strain. The zones of inhibition were between 8 and $10 \mathrm{~mm}$ and were not influenced by the $\mathrm{pH}$ or the amount of FSsg (at $4 \mathrm{mg} / \mathrm{mL}$ and $8 \mathrm{mg} / \mathrm{mL}$ ). Also, we mention that the zones of inhibition did not change their size after storing the plates for another 3 days at the room temperature (in wet chambers). No inhibitory effect on $E$. coli strain was found.

The FSpp was investigated in AgNPs neutral medium (pH-7) and in AgNPs alkaline medium (pH-12), versus FSpp content at the same amount of $0.25 \mathrm{mM} \mathrm{AgNPs}$, in these aqueous media. Aspects of the mode of action of the FSpp product on tested strains are shown in Table 2 and Figs 10a and 10b.

Table 2

THE FSpp CONTENT OF COMPOSITE (PRODUCT)/SAMPLE PREPARED IN TWO MEDIA OF $p$ H 7 AND DISTINCTLY $p \mathrm{H}$ 12, AT THE SAME CONTENT 0.25 mM AgNPs, AND THE DIAMETER OF ZONES OF INHIBITION AT 24 h;

TESTED STRAINS: $S$. aureus AND E. coli.

\begin{tabular}{|c|c|c|c|c|}
\hline \multirow{4}{*}{ Tested strains } & \multicolumn{4}{|c|}{ Composite (product) characteristics } \\
\hline & \multicolumn{2}{|c|}{$\begin{array}{c}\text { AgNPs in } \mathrm{pH}-7 \text { medium, versus FSpp } \\
\text { content }\end{array}$} & \multicolumn{2}{|c|}{$\begin{array}{l}\text { AgNPs in aqueous medium of } \mathrm{pH}-12 \text {, } \\
\text { versus FSpp content }\end{array}$} \\
\hline & \multicolumn{4}{|c|}{ Diameter of inhibition areas $(\mathrm{mm})$ for the four wells } \\
\hline & $\mathbf{1}(4 \mathrm{mg}$ FSpp $/ \mathrm{mL})$ & $3(8 \mathrm{mg}$ FSpp /mL) & $2(4 \mathrm{mg} \mathrm{FSpp} / \mathrm{mL})$ & $4(8 \mathrm{mg}$ FSpp $/ \mathrm{mL})$ \\
\hline S. aureus $6538 \mathrm{P}$ ATCC & 10 & 9 & 10 & 9 \\
\hline E. coli 10536 ATCC & 0 & 0 & 0 & 0 \\
\hline
\end{tabular}

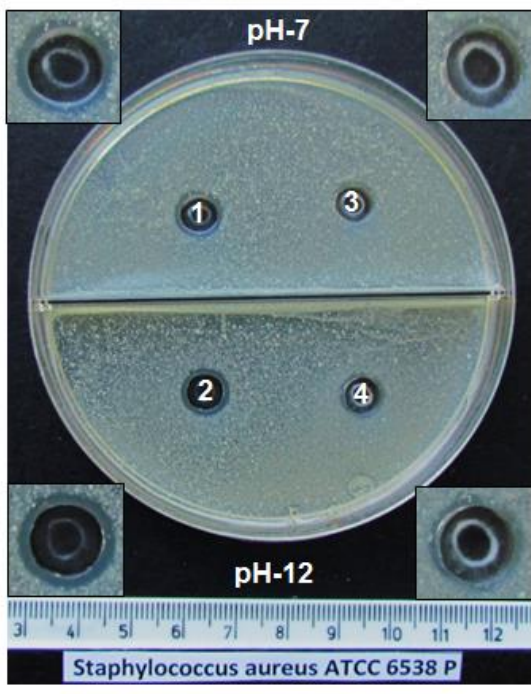

$\mathrm{a}$

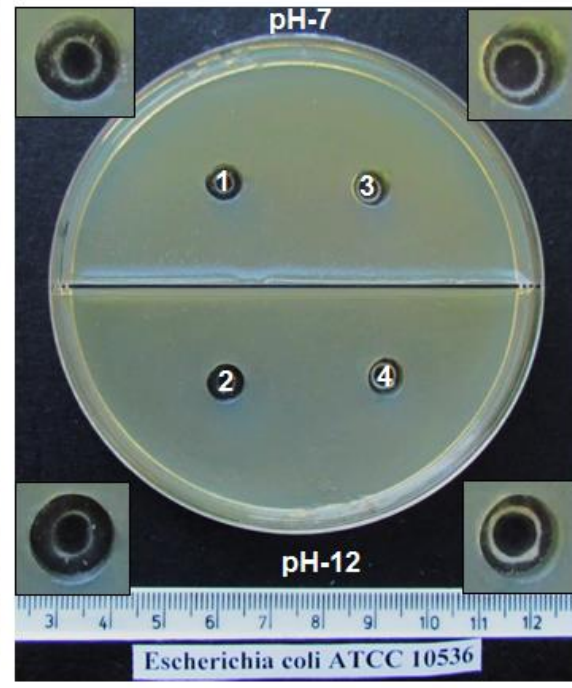

b
Fig. 10. Inhibition zones for Staphylococcus aureus 6538P ATCC (a) and lack of inhibition for Escherichia coli 10536 ATCC (b), versus pH value and FSpp content in aquous medium. Wells are numbered according to their FSpp content and $p \mathrm{H}$ value, (Table 2); well 1: $4 \mathrm{mg}$ of FSpp/mL, $p \mathrm{H}$ 7; well 2: $4 \mathrm{mg}$ FSpp/mL, $p \mathrm{H}$ 12; well 3: $8 \mathrm{mg} \mathrm{FSpp} \mathrm{/mL,} p \mathrm{H}$ 7; well

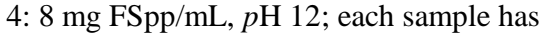
the same content of $0.25 \mathrm{mM}$ AgNPs. Insets: magnified images for each well 
From the analysis of the data listed in Table 2 and Figs 10a and 10b, it can be determined that the FSpp product also showed inhibitory effect only for the $S$. aureus strain. The zones of inhibition were between 9 and $10 \mathrm{~mm}$ and were not influenced by the $\mathrm{pH}$ or the amount of FSpp $(4 \mathrm{mg} / \mathrm{mL}$ and $8 \mathrm{mg} / \mathrm{mL})$. The zones of inhibition did not change their size after storing the plates for another 3 days at the room temperature (in wet chambers). It may also be noted the lack of inhibitory effect on the E. coli strain.

Testing was also performed with FSsg and FSpp products without AgNPs, prepared in pure water as well as in aqueous medium of $\mathrm{pH}-7$ and $\mathrm{pH}-12$. No inhibition zones were found under any circumstances.

The low content of AgNPs was chosen to determine the influence of FSsg and FSpp on antibacterial effect of AgNPs. It was found that the presence of nano forsterite in various aquoeus systems studied improved somehow the antibacterial effect of AgNPs. The antibacterial effect of AgNPs in aqueous systems, at the chosen content in silver, was between 8 and 9 for E. coli and S. aureus, respectively.

Earliest studies have recommended forsterite $\left(\mathrm{Mg}_{2} \mathrm{SiO}_{4}\right)$ for dental and bone implant applications based on its biological properties (biocompatibility and bioactivity) [22].

Data on the antibacterial activity of pure forsterite are scarce. A study using the agar gel diffusion method and forsterite revealed an inhibitory effect against the tested bacteria. The induced effect was more intense for S. aureus, compared to E. coli, noting that forsterite can be used to cover the surface of implants or as a bactericidal bioceramic to prevent bacterial infections, inhibiting biofilm formation [23].

Our in vitro study shows that FSsg and FSpp carrying AgNPs have been effective in inducing an inhibitory effect on $S$. aureus strain (Gram positive) and ineffective against $E$. coli strain (Gram negative). The difference in efficiency may be due, among other things, to the differences in cell wall structure, which is simpler in Gram positive bacteria and more complex in Gram negative bacteria. On the other hand, the antibacterial mechanism of AgNPs is very complex as recently demonstrated [24-26]. Certainly, the nanostructured materials, like nano forsterite, used as carrier of AgNPs are offering new opportunities for orthopedic implant applications [27], particularly against bone infections.

The inhibitory effect of synthesized forsterite, FSsg and FSpp, variants with AgNPs was found only on the S. aureus strain, the zones of inhibition being between 8 and $10 \mathrm{~mm}$, and more intensely expressed in the FSpp product. The difference between FSsg and FSpp can be related with the size of nanoparticles within these nanomaterials. For instance, FSpp contains smaller particles than FSsg and in consequence, FSpp possesses a larger surface of forsterite nanoparticles for the interaction with AgNPs, avoiding the tendency of AgNPs to make aggregates, and thus facilitating Ag ions release in the aqueous medium.

However, the inhibitory effect of FSsg-AgNPs and FSpp-AgNPs composites was not significantly influenced by neutral $\mathrm{pH}-7$ and alkaline $\mathrm{pH}-12$ or by the quantity of fosterite $/ \mathrm{mL}$ (i.e., $4 \mathrm{mg} / \mathrm{mL}$, respectively $8 \mathrm{mg} / \mathrm{mL}$ ) present in various samples/products. Thus, an optimal forsterite amount of $4 \mathrm{mg} / \mathrm{mL}$ was recorded in this study.

Forsterite, FSsg or FSpp, used only in pure water as well as in neutral medium (pH-7) and alkaline medium (pH-12), namely in the absence of AgNPs, had no inhibitory effect against the bacterial strains tested.

\section{Conclusions}

Definitely, forsterite nanomaterials, FSsg and FSpp, originally synthesized in this study can be used as carriers for AgNPs against $S$. aureus, particularly as antimicrobial coating composite on metallic implants. Moreover, these forsterite nanomaterials, FSsg and FSpp, can also release in vivo $\mathrm{Mg}$ and $\mathrm{Si}$, that are essential elements for bone development.

\section{References}

1. CREMET, L., BROQUET, A., BRULIN, B., JACQUELINE, C., DAUVERGNE, S., BRION, R., ASEHNOUNE, K., CORVEC, S., HEYMANN, D., CAROFF, N., FEMS, Pathog. Dis., 73, nr. 8, 2015, p. 1.

2. KUMAR, S., SENGUPTA, M., HADA, V., SARKAR, S., BHATTA, R., SENGUPTA, M., Int. J. Sci. Stud., 5, nr. 8, 2017 , p. 44.

3. AHMED, W., ZHAI, Z., GAO, C., Mater. Today Bio, 2, article nr. 100017, 2019, p.1.

4. SUNDRARAJAN, M., SURESH, J., GANDHI, R. R., Dig. J. Nanomater. Bios., 7, nr. 3, 2012, p. 983.

5. JIN, T., HE, Y., J., Nanopart. Res., 13, nr. 12, 2011, p. 6877.

6. MOGHANIAN, A., SEDGHI, A., GHORBANOGHLI, A., SALARI, E., Ceram. Int., 44, nr. 8, 2018, p.9422.

7. SAQAEI, M., FATHI, M., EDRIS, H., MORTAZAVI, V., Mater. Sci. Eng. C, 56, 2015, p. 409.

8. CHOUDHARY, R., CHATTERJEE, A., VENKATRAMAN, S. K., KOPPALA, S., ABRAHAM, J., SWAMIAPPAN, S., Bioact. Mater., 3, nr. 3, 2018, p. 218

9. GOREA, M., NAGHIU, M. A., AVRAM, A., PETEAN, I., TOMOAIA-COTISEL, M., Stud. Univ. Babes-Bolyai Chem., 64, nr. 2, 2019 , p. 383. 10. NAGHIU, M. A., GOREA, M., MUTCH, E., KRISTALY, F., TOMOAIA-COTISEL, M., J. Mater. Res. Technol., 29, nr. 7, 2013 , p. 628.

11. FURTOS, G., NAGHIU, M. A., DECLERCQ, H., GOREA, M., PREJMEREAN, C., PANA, O., TOMOAIA-COTISEL, M., J. Biomed. Mater.

Res. B, 104B, nr. 7, 2016, p. 1290.

12. GOREA, M., NAGHIU, M.A., AVRAM, A., PETEAN, I., MOCANU, A., TOMOAIA-COTISEL, M., Rev. Chim. (Bucharest), in press 2020.

13. NAGHIU, M. A., GOREA, M., KRISTALY, F., TOMOAIA-COTISEL, M., Ceram.-Silikaty, 58, nr. 4, 2014 , p. 303. 
14. RAPUNTEAN, S., BALINT, R., PALTINEAN, G. A., TOMOAIA, G., MOCANU, A., RACZ, C. P., HOROVITZ, O., TOMOAIA-COTISEL, M., Stud. Univ. Babes-Bolyai Chem., 63, nr. 3, 2018, p. 73.

15. RANOSZEK-SOLIWODA, K., TOMASZEWSKA, E., SOCHA, E., KRZYCZMONIK, P., IGNACZAK, A., ORLOWSKI, P., KRZYZOWSKA, M., CELICHOWSKI, G., GROBELNY, J., J., Nanopart. Res., 19, 2017, p. 273.

16. GOGA, F., FORIZS, E., AVRAM, A., ROTARU, A., LUCIAN, A., PETEAN, I., MOCANU, A., TOMOAIA-COTISEL, M., Rev. Chim. (Bucharest), 68, no. 6, 2017, p. 1193.

17. GOGA, F., FORIZS, E., BORODI, G., TOMOAIA, G., AVRAM, A., BALINT, R., MOCANU, A., HOROVITZ, O., TOMOAIA-COTISEL, M., Rev. Chim. (Bucharest), 68, no. 12, 2017, p. 2907.

18. RAPUNTEAN, S., FRANGOPOL, P. T., HODISAN, I., TOMOAIA, G., OLTEAN-DAN, D., MOCANU, A., PREJMEREAN, C., SORITAU, O., RACZ, L. Z., TOMOAIA-COTISEL, M., Rev. Chim. (Bucharest), 69, nr. 12, 2018, p. 3537.

19. HODISAN, I., PREJMEREAN, C., BURUIANA, T., PRODAN, D., COLCERIU, L., PETEAN, I., FURTOS, G., PREJMEREAN, V., TOMOAIA-COTISEL, M., Rev. Chim. (Bucharest), 69, no. 10, 2018, p. 2693.

20. BAUER, A.W., PERRY, D. M., KIRBY, W. M. M., AMA Arch. Intern. Med., 104, nr. 2, 1959, p. 208.

21. MOCANU, A., FURTOS, G., RAPUNTEAN, S., HOROVITZ, O., FlORE, C., GARBO, C., DANISTEANU, A., RAPUNTEAN, G., PREJMEREAN, C., TOMOAIA-COTISEL, M., Appl., Surf. Sci., 298, 2014, p. 225.

22. PRAKASH, P. S., PAWAR, S. J., TEWARI, R. P., Proc. Inst. Mech. Eng. Pt. L J. Mater. Des. Appl., 233, nr. 6, 2017, p. 1227.

23. CHOUDHARY, R., MANOHAR, P., VECSTAUDZA, J., YÁÑEZ-GASCÓN, M. J., PÉREZ SÁNCHEZ, H., NACHIMUTHU, R., LOCS, J., SWAMIAPPAN, S., Mater. Sci. Eng. C, 77, 2017, p. 811.

24. ALVAREZ, M. M., AIZENBERG, J., ANALOUI, M., ANDREWS, A. M., BISKER, G., BOYDEN, E. S., KAMM, R. D., KARP, J. M., MOONEY, D. J., OKLU, R., PEER, D., STOLZOFF, M., STRANO, M. S., TRUJILlO-DE-SANTIAGO, G., WEBSTER, T. J., WEISS, P. S., KHADEMHOSSEINI, A., ACS Nano, 11, 2017, p. 5195.

25. LI, B., WEBSTER, T. J., J. Orthop. Res., 36, nr. 1., 2018, p. 22.

26. NAVARRO GALLON, S. M., ALPASLAN, E., WANG, M., LARESE-CASANOVA, P., LONDONO, M. E., ATEHORTÚA, L., PAVÓN, J. J., WEBSTER, T. J., Mater. Sci. Eng. C, 99, 2019, p. 685.

27. OLTEAN-DAN, D., DOGARU, G. B., TOMOAIA-COTISEL, M., APOSTU, D., MESTER, A., BENEA, H. R. C., PAIUSAN, M. G., JIANU, E. M., MOCANU., A., BALINT, R., POPA, C. O., BERCE, C., BODIZS, G. I., TOADER, A. M., TOMOAIA, G., Int. J. Nanomedicine, 14, 2019, p. 5799.

Manuscript received: 3.10 .2019 